\title{
Effects of Pulmonary Edema on Regional Blood Volume and Red Blood Cell Transit Time

\author{
Comparison of High Pressure and Oleic Acid-induced Edema
}

\author{
J. Y. Tsang, J. S. G. Montaner, and J. C. Hogg \\ University of British Columbia, Pulmonary Research Laboratory, St. Paul's Hospital, Vancouver, British Columbia, V6Z 1 Y6 Canada
}

\begin{abstract}
The present study was designed to determine the effects of pulmonary vascular pressure, vascular injury, and pulmonary edema on regional blood volume (Vr) and regional red blood cell (RBC) transit time (Tr) in the lung. The experiments were carried out in 15 dogs. Six served as controls, six had oleic acid-induced pulmonary edema (OAPE), and three had high pressure pulmonary edema (HPPE). Regional blood flow (Qr) was measured with ${ }^{99} \mathrm{Tc}$ macroaggregates, $\mathrm{Vr}$ with ${ }^{51} \mathrm{Cr}$ homologous $\mathrm{RBC}$, and regional transit time was calculated (Vr/Qr). The dogs were killed, and the lungs removed and sampled completely. Regional extravascular lung water (EVLW) was measured in grams per gram of dry lung and ranged from $3.7 \pm 1.1$ in the control group to 6.0 \pm 1.3 in OAPE and 5.6 \pm 0.6 in HPPE. The data show that in normal lungs, increased $Q r$ was associated with a recruitment of blood volume. In OAPE, data show that regional blood volume was decreased and that vascular injury and edema formation interfered with a further increase in Vr as Qr increased. In HPPE, Vr has already fully distended and it changed little with increased blood flow. We conclude that oleic acid-induced pulmonary injury and edema interfere with vascular recruitment and shorten regional RBC transit times. HPPE, on the other hand, is associated with normal regional $R B C$ transit times because the vessels are fully recruited.
\end{abstract}

\section{Introduction}

Under normal conditions the pulmonary circulation is a low pressure, compliant system where pulmonary vascular resistance falls as total pulmonary blood flow increases (1). This fall in resistance is associated with dilatation and recruitment of the pulmonary vasculature so that blood volume increases with blood flow (2-4). In a previous study from this laboratory (5), it was shown that regional blood volume $(\mathrm{Vr})^{1}$ increases with

Address correspondence to Dr. Hogg.

Received for publication 26 December 1984 and in revised form 6 February 1986.

1. Abbreviations used in this paper: BP, blood pressure; EVLW, regional extravascular lung water, HPPE, high pressure pulmonary edema; OAPE, oleic acid-induced pulmonary edema; $\mathrm{Pi}$, interstitial pressure; Ppa, mean pulmonary artery pressure; Ppaw, mean pulmonary wedge pressure; $\mathrm{PvO}_{2}$, central venous oxygen tension; Qr, regional blood flow; Qs/Qt, shunt fractions; Qt, cardiac output; RA, right atrium; RBC, red blood cells; $\mathrm{Tr}$, regional transit time; $\mathrm{Vr}$, regional blood volume; $\mathrm{Vr}^{\mathbf{0}}$, basal pulmonary blood volume.

J. Clin. Invest.

(c) The American Society for Clinical Investigation, Inc.

0021-9738/86/06/1780/06 \$1.00

Volume 77, June 1986, 1780-1785 increasing regional blood flow (Qr) and regional transit times ( $\mathrm{Tr}$ ) of the red blood cells remains relatively constant. The present studies extend these observations to edematous lungs to determine whether different physiological states of the pulmonary vasculature associated with pulmonary edema can interfere with regional vascular dilatation and/or recruitment. Oleic acid was used to produce increased permeability low pressure pulmonary edema and fluid overload was used to produce high pressure pulmonary edema. The data show that in oleic acid-induced pulmonary edema (OAPE), $\mathrm{Vr}$ is low and remains low with increasing regional blood flow. In high pressure pulmonary edema (HPPE), on the other hand, $\mathrm{Vr}$ was high and changed little with higher Qr because the pulmonary vasculature had already been fully recruited. This has the effect of shifting the distribution of $\mathrm{Tr}$ to shorter than normal values in OAPE, while in HPPE regional transit times have normal values and a more even distribution. We conclude that pulmonary edema and possibly vascular injury, as observed in OAPE, interfere with vascular recruitment and shortens the regional transit times when vascular pressures are within the normal range.

\section{Methods}

Mongrel dogs weighing $25 \pm 5 \mathrm{~kg}$ were anesthetized with sodium pentobarbital (25-30 mg/kg i.v.), placed in a supine position, and intubated with a cuffed endotracheal tube. They were ventilated with $100 \% \mathrm{O}_{2}$ by a Harvard animal ventilator at a tidal volume of $12-15 \mathrm{ml} / \mathrm{kg}$ and a respiratory rate of $10-15$ per min to maintain the $\mathrm{PCO}_{2}$ between 35 and 42. A 7 French double lumen Swan-Ganz, thermistor-tipped catheter (Edwards Laboratory, Sandusky, $\mathrm{OH}$ ) was placed in the pulmonary artery under fluoroscopic control in order to measure the mean pulmonary artery pressure (Ppa), mean pulmonary wedge pressure (Ppaw), and the cardiac output $(\mathrm{Qt})$ by the thermodilution technique (6).

A multiple side-hole catheter was placed in the right atrium (RA) to infuse fluid. Two arterial catheters were inserted in the carotid arteries. One was used to monitor the systemic blood pressure (BP), while the second had an inflatable balloon tip and was placed within the descending thoracic aorta so that cardiac afterload could be increased by inflating the balloon. The urinary bladder was emptied and both ureters were ligated to minimize urine output. Vascular pressures were recorded using an 8 channel recorder (model 77528, Hewlett-Packard Co., Palo Alto, CA). Blood gas samples and hemoglobin measurements were obtained under various experimental conditions (see below) for the calculation of the corresponding shunt fraction $(Q s / Q t)$. All pressures were referred to the mid-chest position. Warming blankets were used to maintain the animal body temperature between $36^{\circ}$ and $38^{\circ} \mathrm{C}$ and sodium bicarbonate was used during the experiment to maintain plasma pH between 7.35 and 7.45 .

The baseline hemodynamic measurements were obtained $\sim \mathbf{4 0}$ min after the induction of anesthesia. The animals were then divided into three groups. Group $1(n=6)$ served as control and was monitored for $2 \mathrm{~h}$ without further intervention. An experimental model of low pressure pulmonary edema was produced in group II $(n=6)$ by injecting oleic acid $(0.08 \mathrm{ml} / \mathrm{kg}$ suspended in $5 \mathrm{ml}$ of $0.9 \%$ saline i.v.) (7) in a bolus 
through the multiple sided-holed catheter in the RA. High pressure pulmonary edema (HPPE) was produced in group III $(n=3)$ by inflating the balloon-tipped catheter in the descending thoracic aorta with 1-3 $\mathrm{ml}$ of saline and rapidly infusing Ringer's lactate solution (25\% of body weight) over $2 \mathrm{~h}$. Pulmonary artery pressure was kept within the range of $25-45 \mathrm{~cm}$ of $\mathrm{H}_{2} \mathrm{O}$. Further modification of the cardiac afterload was achieved by varying the degree of inflation of the balloon on the aortic catheter.

$2 \mathrm{~h}$ after the baseline measurements were obtained, the measurements of Ppa, Ppaw, BP, hemoglobin, arterial and venous blood gas were repeated. Qt was measured and albumin macroaggregates; labeled with ${ }^{99 \mathrm{~m}} \mathrm{Tc}$, were injected into the RA to mark the regional blood flow. The physiological shunt fraction $(\mathrm{Qs} / \mathrm{Qt})$ was calculated by the following equation (8): (Qs) $/(\mathrm{Qt})=(\mathrm{Cc}-\mathrm{Ca}) /(\mathrm{Cc}-\mathrm{Cv}) \times 100 \%$, where $\mathrm{Cc}, \mathrm{Ca}$, and $\mathrm{Cv}$ are the oxygen content in the pulmonary capillary blood, the arterial blood, and the central venous blood, respectively, with the inspired oxygen concentration at $100 \%$.

Autologous red blood cells labeled with ${ }^{51}$ Chromium were then injected to mark the intravascular space. Four samples of blood, $\sim 5 \mathrm{ml}$ each, were obtained after the complete equilibration of ${ }^{51} \mathrm{Cr}$ red blood cells with the circulating blood volume. The dogs were then placed in deep anesthesia with intravenous pentobarbitol and killed with a bolus of saturated $\mathrm{KCl}$. The chest and pericardial sac were opened and the heart pulled up so that the major pulmonary vessels could be tied off with a single snare. The lungs were kept in an inflated state by clamping the trachea while they were being removed. An endotracheal tube was inserted and tied into the open end of the trachea, which was then unclamped, so that the lungs could be inflated to a transpulmonary pressure of $20 \mathrm{~cm}$ of $\mathrm{H}_{2} \mathrm{O}$. They were maintained at this volume using a constant airflow with a $\mathrm{T}$ piece to underwater seal while they were rapidly frozen over liquid nitrogen fumes in an insulated box. The frozen lungs were cut into 2-cm slices from the dependent (dorsal) surface to the anterior (sternal) surface. Each slice was further divided into smaller regional samples that were placed in preweighed vials. These vials were reweighed to obtain the wet weight of the samples and counted in a model 7000 gamma scintillation counter (Beckman Instruments, Inc., Fullerton, CA) for all the isotopes with appropriate corrections for decay, background, and overlap. The vials were then placed in a microwave oven for several days and the samples dried to a constant weight so that they could be reweighed to determine the dry weight of the samples. Having measured the ${ }^{51} \mathrm{Cr}$ counts per milliliter of blood drawn at the end of the experiment, the blood volume in each regional sample was then calculated from the ${ }^{51} \mathrm{Cr}$ activity in the same sample and the amount of blood water was substracted from each sample to obtain the extravascular lung water per gram of blood free dry lung (EVLW). The Qr to each lung sample was calculated using the formula: $\mathrm{Qr}=\left[{ }^{99 \mathrm{~m}} \mathrm{Tc}\right.$ counts in the sample $\times$ cardiac output $(\mathrm{ml} / \mathrm{s})] /\left[\right.$ total ${ }^{99 m} \mathrm{Tc}$ counts in the lung $\left.(\mathrm{ml} / \mathrm{s})\right]$. Both the $\mathrm{Qr}$ in milliliters per second and the $\mathrm{Vr}$ in milliliters were expressed in values per gram of blood-free dry lung. $\mathrm{Vr}$ was then plotted against $\mathrm{Qr}$ for each group so that their correlation could be assessed. $\mathrm{Tr}$ in seconds, defined as $\operatorname{Vr}(\mathrm{ml}) / \mathrm{Qr}(\mathrm{ml} / \mathrm{s})$, was also calculated for each sample (5). The data were expressed as mean \pm standard deviation unless otherwise indicated, and a difference at the level of $P<0.05$ was considered significant.

\section{Results}

Table I shows the hemodynamic data, the hemoglobin, and the calculated shunt fraction $(\mathrm{Q} / \mathrm{Q} \mathrm{Q})$ of the dogs under various experimental conditions. The values of the pulmonary vascular pressures and cardiac outputs listed in Table I represent hemodynamic conditions when $\mathrm{Qr}$ and $\mathrm{Vr}$ were labeled with radioactive markers. In the control and OAPE group, the pulmonary vascular pressures are comparable $(\mathrm{Ppa}=17.8 \pm 4.8$ and $19.7 \pm 2.4 \mathrm{~cm} \mathrm{H}_{2} \mathrm{O}$, respectively $[P>0.05]$, and Ppaw $=5.8 \pm 3.6$ and $5.0 \pm 1.8 \mathrm{~cm} \mathrm{H}_{2} \mathrm{O}$, respectively $\left.[P>0.05]\right)$. However, in the HPPE group, both of these pressures are elevated when compared with control $\left(\mathrm{Ppa}=35.0 \pm 5.3 \mathrm{~cm} \mathrm{H}_{2} \mathrm{O}\right.$, and Ppaw $=22.0 \pm 3.0$ $\left.\mathrm{cm} \mathrm{H}_{2} \mathrm{O}[P<0.05]\right)$ because of the Ringer's lactate infusion and the inflation of intraaortic balloon. Qt is the highest in the HPPE group $(\mathrm{Qt}=4.13 \pm 0.40$ liters $/ \mathrm{min})(P<0.05)$ due to the hyperdynamic state with vascular expansion. The shunt fraction (Qs/ $\mathrm{Qt})$ is the lowest in the control group $(\mathrm{Qs} / \mathrm{Qt}=14.3 \pm 6.5 \%)$ and is increased in the two edema groups $(\mathrm{Qs} / \mathrm{Qt}=29.7 \pm 10.1 \%$ in OAPE group $[P<0.05]$ and $35.1 \pm 5.2 \%$ in the HPPE group [ $P$ $<0.05])$. The hemoglobin in the HPPE group is decreased $(\mathrm{Hb}$ $=8.9 \pm 1.3 \mathrm{~g} \%$ ) because of the hemodilution caused by the Ringer's lactate infusion. Table II shows the data on gas exchange in the three groups of animals. The central venous oxygen tension $\left(\mathrm{PvO}_{2}\right)$ of all these animals is higher than the usual physiological range at room air because they were all ventilated at $100 \%$ oxygen.

Table III shows the number of lung samples taken for each experiment, the Qr, $\mathrm{Vr}$, and the amount of extravascular lung water (EVLW) present. These values are presented as the mean \pm 1 SD for each animal and for all of the animals in each group to show the range of variability of these parameters both within and among the experiments. Qr is the highest in the HPPE group $(2.5 \pm 1.6 \mathrm{ml} / \mathrm{s}$ per $\mathrm{g}$ dry lung $[P<0.05])$ because the cardiac output is increased (Tables I and III). The $\mathrm{Vr}$ is also high in this group $(4.6 \pm 1.6 \mathrm{ml} / \mathrm{g}$ dry lung $[P<0.05])$ because of the vascular engorgement with high pressure pulmonary edema. $\mathrm{Vr}$ is the lowest in the OAPE group $(\mathrm{Vr}=1.2 \pm 0.5 \mathrm{ml} / \mathrm{g}$ dry lung; $P<0.05)$. We also compare our data with Fig. 1 of Muir et al. (9) who studied histology in relation to gravemetric measurements of edema and found that interstitial edema was present when the wet to dry ratio was 6.5 . This value approximates our data of wet to dry ratio of $6.9 \pm 1.1$ and $6.7 \pm 0.4$ from the OAPE and HPPE groups, respectively. From these wet to dry ratios and the $\mathrm{Cr}^{51}$-labeled blood volume, the EVLWs were calculated as $6.0 \pm 1.3 \mathrm{~g} / \mathrm{g}$ dry lung for the OAPE group and $5.6 \pm 0.6 \mathrm{~g} / \mathrm{g}$ dry lung for the HPPE group (Table III). This shows that interstitial edema was present in both our OAPE group and the HPPE group.

Table I. Hemodynamic Data at the Time When Qr and Vr Were Labeled

\begin{tabular}{|c|c|c|c|c|c|c|}
\hline $\begin{array}{l}\text { Experimental } \\
\text { conditions }\end{array}$ & $\begin{array}{l}\text { No. of } \\
\text { experiments }\end{array}$ & Ppa & Ppaw & Qt & $\begin{array}{l}\mathrm{Hb} \\
\left(\mathrm{g} / 100 \mathrm{~cm}^{3}\right)\end{array}$ & $\mathrm{Qs} / \mathrm{Qt}$ \\
\hline & & $\mathrm{Cm} \mathrm{H}_{2} \mathrm{O}$ & $\mathrm{Cm} \mathrm{H}_{2} \mathrm{O}$ & liters/min & & $\%$ \\
\hline Control & 6 & $17.8 \pm 4.8$ & $5.8 \pm 3.6$ & $2.79 \pm 1.01$ & $14.8 \pm 1.6$ & $14.3 \pm 6.5$ \\
\hline OAPE & 6 & $19.7 \pm 2.4$ & $5.0 \pm 1.8$ & $3.43 \pm 0.74$ & $13.4 \pm 1.6$ & $29.7 \pm 10.1^{*}$ \\
\hline HPPE & 3 & $35.0 \pm 5.3^{*}$ & $22.0 \pm 3.0^{*}$ & $4.13 \pm 0.40^{*}$ & $8.9 \pm 1.3^{*}$ & $35.1 \pm 5.2^{*}$ \\
\hline
\end{tabular}

See Result section for detailed statistical analysis. * Indicates statistical difference from control $(P<0.05)$. 
Table II. Blood Gas Data

\begin{tabular}{llllllll}
\hline $\begin{array}{l}\text { Experimental } \\
\text { condition }\end{array}$ & $\begin{array}{l}\text { No. of } \\
\text { animals }\end{array}$ & $\mathrm{pH}$ & $\mathrm{Pa}_{2}$ & $\mathrm{PCO}_{2}$ & $\mathrm{HCO}_{3}$ & $\begin{array}{l}\text { Percent } \\
\text { saturation }\end{array}$ & $\mathrm{P}_{\mathrm{vo}_{2}}$ \\
\hline Control & 6 & $7.37 \pm 0.10$ & $462.8 \pm 92.2$ & $42.3 \pm 10.0$ & $21.0 \pm 1.8$ & $99.9 \pm 0.0$ & $63.0 \pm 12.8$ \\
OAPE & 6 & $7.35 \pm 0.04$ & $275.8 \pm 132.0$ & $36.2 \pm 2.0$ & $19.8 \pm 1.3$ & $98.7 \pm 3.3$ & $53.5 \pm 5.9$ \\
HPPE & 3 & $7.39 \pm 0.08$ & $383.7 \pm 31.0$ & $30.0 \pm 2.7$ & $18.7 \pm 4.0$ & $99.9 \pm 0.0$ & $73.0 \pm 17.0$
\end{tabular}

All the parameters listed represent the values of the arterial blood except $\mathbf{P}_{\mathrm{vo}_{2}}$, where it represents the oxygen tension of the central venous blood.

The relationships between regional blood volume and regional blood flow under these experimental conditions (Figs. 13) show that regional blood volume increases with regional blood flow in the control group but not in the oleic acid pulmonary edema group or high pressure pulmonary edema group. Note the differences in the slopes of the three figures.

Regional transit time, defined as: (regional blood volume)/ (regional blood flow) or $(\mathrm{Vr})(\mathrm{ml}) /(\mathrm{Qr})(\mathrm{ml} / \mathrm{s})$, was calculated for all of the lung samples and represents the average duration (in seconds) that the red blood cells spend in each region. Blood vessels of various sizes are included in these regions. The range of regional transit times in the control group is similar to that previously reported (5). The regional transit times were assessed by using the distribution force multiple comparison method based on Krustal-Wallis rank sums (10). This shows that in the OAPE group the regional transit time was $1.9 \pm 1.8 \mathrm{~s}$, which is significantly lower than the control and the HPPE group ( $P$ $<0.05$ ) (Table IV). Note that $\mathrm{Vr}$ in this group is also the lowest and it does not increase with increasing $\mathrm{Qr}$ (Fig. 2, slope $=0.11$ ).
The histograms of the distribution of these regional transit times (Figs. 4-6) show that a heterogeneity in regional transit times was observed in all three groups. OAPE also caused a shift in the distribution towards shorter regional transit times. On the other hand, HPPE was associated with regional transit times comparable with the control values $(P>0.05)$ and a more even distribution.

\section{Discussion}

As total pulmonary blood flow increases, the pulmonary vascular resistance decreases (1). Several studies have attributed this phenomenon to the recruitment of the pulmonary vasculature (24). Previous studies from this laboratory (5) have shown that the regional blood volume increases with increasing blood flow, and the data from the control animals of the present study (Fig. 1) confirm this observation. However, when edema and vascular injury were present there was little further increase in $\mathrm{Vr}$ with

Table III. Data of the Regional Lung Samples

\begin{tabular}{|c|c|c|c|c|c|}
\hline Experimental conditions & Dog no. & $\begin{array}{l}\text { No. of regional } \\
\text { samples }\end{array}$ & $Q^{*}$ & $\mathrm{Vr}^{*}$ & EVLW* \\
\hline & & & $m l / s-g$ & $\mathrm{ml} / \mathrm{g}$ & $g$ water $/ g$ dry lung \\
\hline \multirow[t]{6}{*}{ Control } & 1 & 84 & $1.5 \pm 0.7$ & $2.2 \pm 0.8$ & $2.8 \pm 0.4$ \\
\hline & 2 & 95 & $0.6 \pm 0.7$ & $1.3 \pm 0.5$ & $3.6 \pm 0.3$ \\
\hline & 3 & 23 & $1.7 \pm 0.8$ & $4.0 \pm 0.7$ & $3.1 \pm 0.5$ \\
\hline & 4 & 28 & $1.3 \pm 0.5$ & $3.3 \pm 0.5$ & $4.0 \pm 0.2$ \\
\hline & 5 & 47 & $2.9 \pm 1.0$ & $5.0 \pm 1.0$ & $4.2 \pm 0.8$ \\
\hline & 6 & 47 & $1.3 \pm 0.5$ & $4.0 \pm 1.4$ & $4.6 \pm 1.0$ \\
\hline Control group value & & 324 & $1.4 \pm 1.0$ & $2.8 \pm 1.6$ & $3.7 \pm 1.1$ \\
\hline \multirow[t]{6}{*}{ OAPE } & 1 & 90 & $1.0 \pm 1.3$ & $1.1 \pm 0.4$ & $6.5 \pm 1.2$ \\
\hline & 2 & 78 & $1.0 \pm 0.5$ & $1.0 \pm 0.3$ & $7.0 \pm 1.3$ \\
\hline & 3 & 85 & $1.3 \pm 0.8$ & $1.6 \pm 0.4$ & $5.6 \pm 0.9$ \\
\hline & 4 & 55 & $1.0 \pm 0.9$ & $1.2 \pm 0.2$ & $5.5 \pm 0.3$ \\
\hline & 5 & 72 & $0.7 \pm 0.5$ & $0.8 \pm 0.2$ & $5.2 \pm 1.2$ \\
\hline & 6 & 37 & $1.4 \pm 2.1$ & $1.8 \pm 0.6$ & $5.8 \pm 1.8$ \\
\hline OAPE group value & & 417 & $1.0 \pm 1.0$ & $1.2 \pm 0.5 \ddagger$ & $6.0 \pm 1.3 \ddagger$ \\
\hline \multirow[t]{3}{*}{ HPPE } & 1 & 39 & $1.7 \pm 1.1$ & $3.4 \pm 0.8$ & $5.6 \pm 0.7$ \\
\hline & 2 & 43 & $2.9 \pm 1.5$ & $6.2 \pm 1.3$ & $5.5 \pm 0.6$ \\
\hline & 3 & 47 & $2.6 \pm 1.8$ & $4.0 \pm 1.2$ & $5.8 \pm 0.6$ \\
\hline HPPE group value & & 129 & $2.5 \pm 1.6 \ddagger$ & $4.6 \pm 1.6 \ddagger$ & $5.6 \pm 0.6 \ddagger$ \\
\hline
\end{tabular}

See text for detailed analysis. * All parameters expressed in values per gram of blood-free dry lung. $¥$ Indicates statistical difference from control $(P<0.05)$. Only group values are compared. 


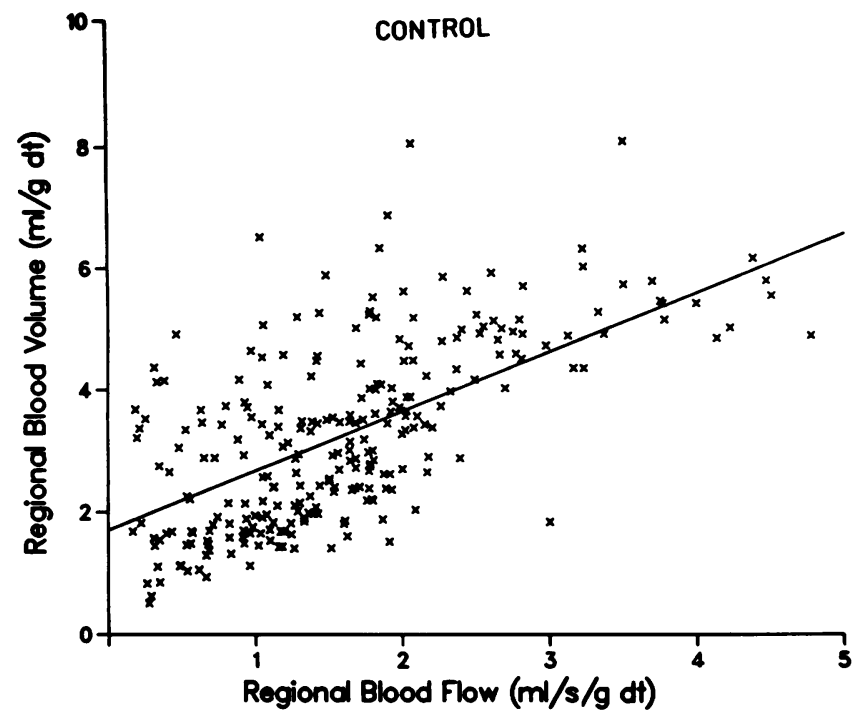

Figure 1. Vr increases with regional blood flow in the control group, indicating that vascular recruitment occurs with increased regional blood flow. $r$, Regression coefficient $(r=0.70$; slope $=1.1$ ).

increased flow, as observed in oleic acid-induced low pressure pulmonary edema (Fig. 2). On the other hand, in high pressure pulmonary edema, vascular recruitment was also limited with increased Qr (Fig. 3), because most of the vessels have been maximally recruited under the circumstances due to the higher vascular pressure (Table I). The intercepts on the $Y$ axis of Figs. 1-3 represent the basal pulmonary blood volumes $\left(\mathrm{Vr}^{0}\right)$ at zero flow, and have values of $1.4,1.1$, and $3.8 \mathrm{ml} / \mathrm{g}$ for the control group, OAPE group, and HPPE group, respectively. It indicates that in the control group, $\mathrm{Vr}^{0}$ is low when there is little flow but can be rapidly recruited as flow increases (slope $=1.1$ ). In the OAPE group, $\mathrm{Vr}^{0}$ is the lowest and remains so even though the flow increases (slope $=0.11$ ). On the other hand, $\mathrm{Vr}^{0}$ is the highest in HPPE, as one may expect, but it increases little as flow increases (slope $=0.32$ ). The intercepts $\mathrm{Vr}^{0}$ approximates $\mathrm{Vr}$ (Table III) better in the OAPE group $\left(\mathrm{Vr}^{0}=1.1 \mathrm{ml} / \mathrm{g}\right.$ vs. $\mathrm{Vr}$ $=1.2 \pm 0.5 \mathrm{ml} / \mathrm{g})$ and in the HPPE group $\left(\mathrm{Vr}^{0}=3.8 \mathrm{ml} / \mathrm{g} \mathrm{vs}\right.$. $\mathrm{Vr}$ $=4.6 \pm 1.6 \mathrm{ml} / \mathrm{g}$ ). However, $\mathrm{Vr}^{0}$ is lower in the control group $\left(\mathrm{Vr}^{0}=1.4 \mathrm{ml} / \mathrm{g}\right.$ and $\left.\mathrm{Vr}=2.8 \pm 1.6 \mathrm{ml} / \mathrm{g}\right)$, indicating that blood volume depends significantly on the status of blood flow when no edema is present.

Under normal circumstances, vascular volume increases when the transmural pressure of the vessels is increased. This can occur either by overcoming the critical opening pressures so that previously closed small blood vessels are recruited or by further distending the vessels that are open (11). The interstitial pressure (Pi) is an important determinant of vascular transmural pressure. As Pi can be expected to rise when edema fluid accumulates in the interstitial space, this will effectively lower the transmural pressure. Staub (12) reported that the sequence of fluid accumulation in the lung is similar in high and low pressure pulmonary edema, with the edema fluid first accumulated in the interstitium and then in the air space. Guyton and his associates measured interstitial pressure using an implanted capsule and suggested that the interstitial pressure increases as fluid accumulates in the lungs $(13,14)$. More recently, Bhattacharya and his colleagues (15) have used micropuncture techniques to measure interstitial pressure at alveolar wall junctions, in the

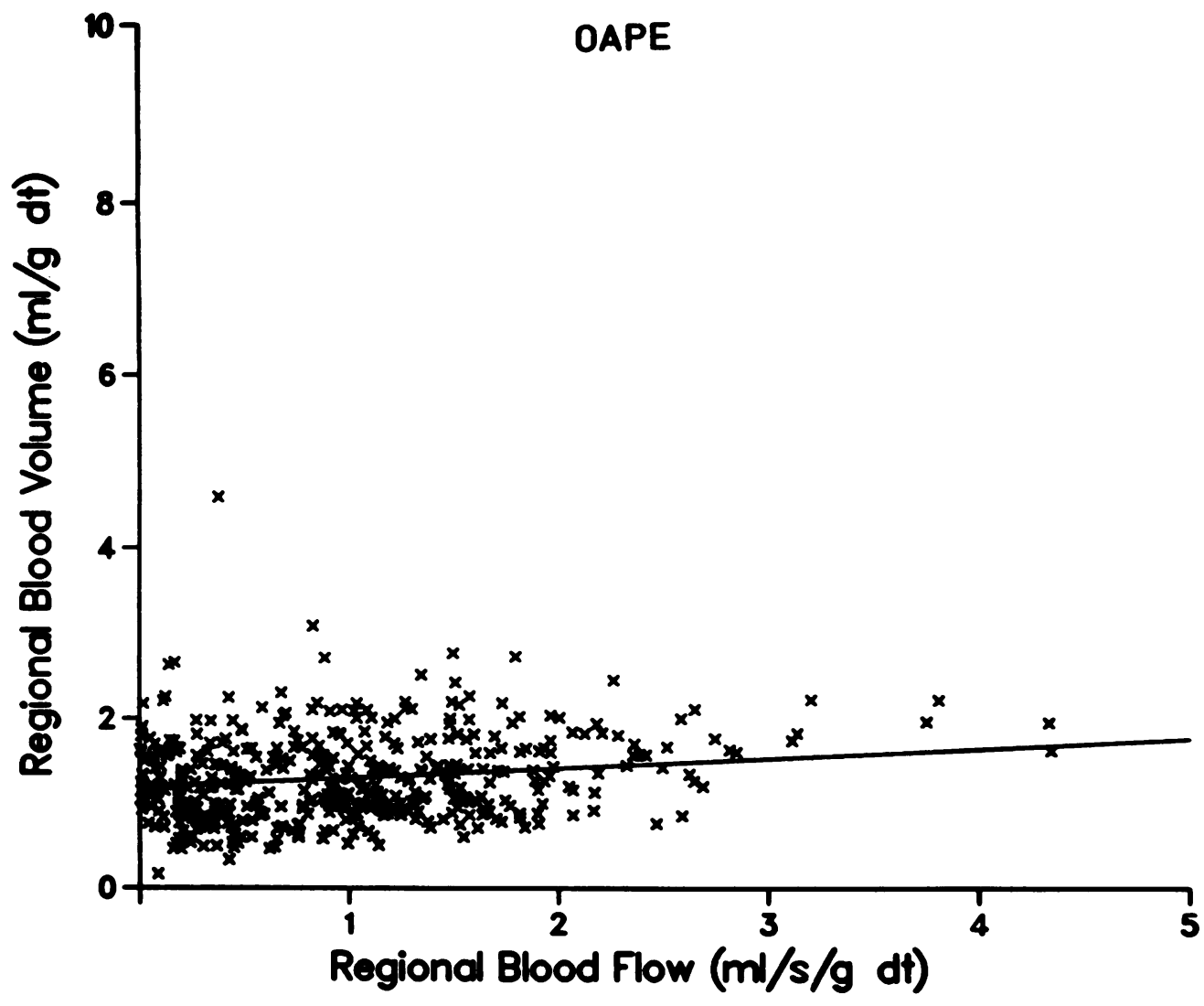

Figure 2. Vr does not increase with regional blood flow in the OAPE group, indicating that vascular recruitment does not occur readily with increased regional blood flow. Note that $\mathrm{Vr}$ is comparatively lower $(r=0.25$; slope $=0.11$ ). 


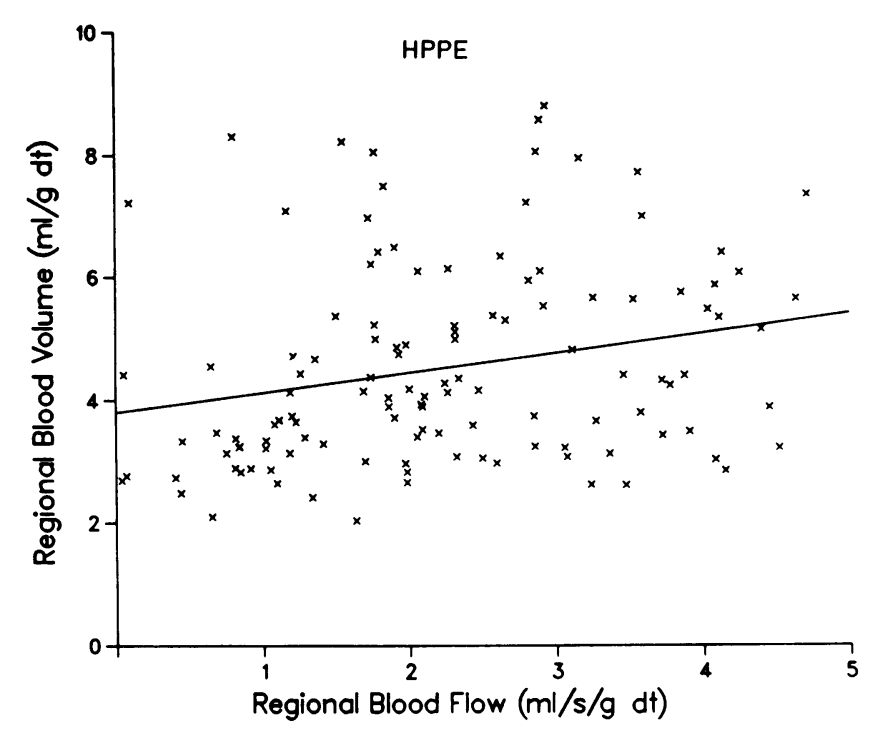

Figure 3. Vr does not increase with regional blood flow in the HPPE group, indicating that vascular recruitment does not occur readily with increased regional blood flow. Note that $\mathrm{Vr}$ is comparatively higher $(r$ $=0.30$; slope $=0.32$ ).

adventitia $\sim 50 \mu \mathrm{m}$ venules, and at the hilum. They found that the interstitial pressures at the alveolar junctions and the adventitia rose from 1.3 to $4.3 \mathrm{~cm} \mathrm{H}_{2} \mathrm{O}$ and 0.3 to $1.4 \mathrm{~cm} \mathrm{H}_{2} \mathrm{O}$, respectively, when lung water was increased from 3.3 to 5.4 $\mathrm{g} / \mathrm{g}$ dry lung. Table III shows that the range of EVLW in the experiments reported here is similar to that in Bhattacharya's study (15) and it is reasonable to assume that there was a similar change in interstitial pressure. This increase in interstitial pressure would have a different effect on OAPE than in HPPE because intravascular pressure was low (Ppaw $=5.0 \pm 1.8$, Table III) in OAPE and high (Ppaw $=22 \pm 3$, Table III) in HPPE. Therefore, an increase in interstitial pressure of $3 \mathrm{~cm}$ of water would substantially lower transmural pressure in OAPE and may account for the observed reduction in vascular volume, whereas it would have little effect on transmural pressure in HPPE. This argument is supported by the observation that the vascular volumes are several times larger in the HPPE group than in the OAPE group (Table III).

In addition to the increased $\mathrm{Pi}$, several other factors could help to explain the reduced $\mathrm{Vr}$ and more rapid $\mathrm{RBC}$ transit in OAPE. It is possible that alveolar flooding is greater in OAPE and that this decreases the volume of the microvessels either by directly decreasing transmural pressure or by inducing local hypoxic vasoconstriction (16). Alternatively, there may have been direct injury to the arteries by the oleic acid (7) that in-

Table IV. Values of the Regional Transit Time

\begin{tabular}{lll}
\hline Experimental conditions & No. of dogs & $\operatorname{Tr}$ (in seconds) \\
\hline Control & 6 & $2.4 \pm 1.4$ \\
OAPE & 6 & $1.9 \pm 1.8^{*}$ \\
HPPE & 3 & $2.3 \pm 1.3$
\end{tabular}

See text for detailed analysis.

* Indicates statistical difference from control $(P<0.05)$.

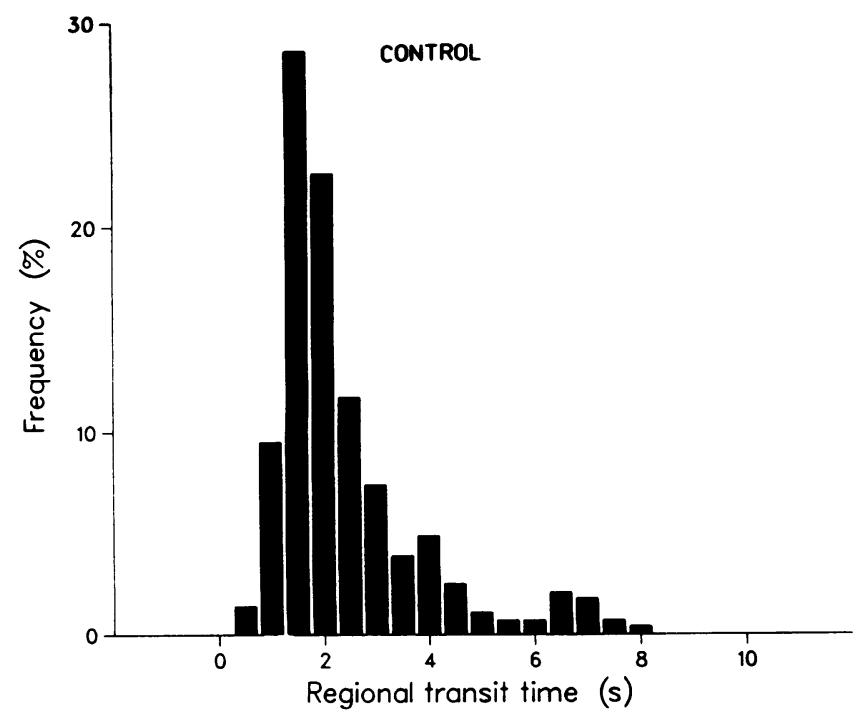

Figure 4. The histogram of regional transit times in the control group.

creased arterial smooth muscle tone to derecruit the distal microvascular bed.

The data show that in OAPE, the transit time of the red blood cells through some of the lung regions becomes short (Table IV), and that the distribution of Tr is shifted to the left of the control group (compare Figs. 4 and 5). In HPPE, where blood volumes and flows are both high (Table III), the regional transit times are comparable to the control (Table IV) and the distribution becomes more even (compare Figs. 4 and 6). Recent studies from our laboratory (17) have shown that when similar amounts of edema are present, and when differences in cardiac output are taken into account (18), there is more interference with gas exchange in OAPE than HPPE. However, as the current literature suggests that diffusion defects contribute little to the abnormalities in gas exchange in OAPE (19), it seems unlikely that the shortened $\mathrm{Tr}$ reported here reduce microvascular transit time sufficiently to interfere with gas exchange.

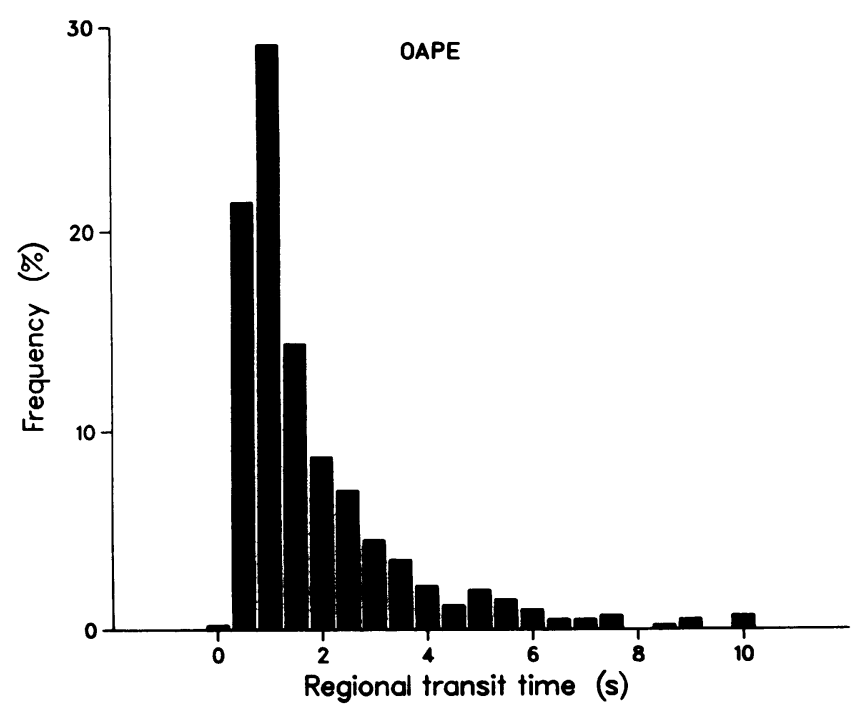

Figure 5. The histogram of regional transit times in the low pressure pulmonary edema group that is shifted to the left of the control group (Fig. 4), $P<0.05$. 


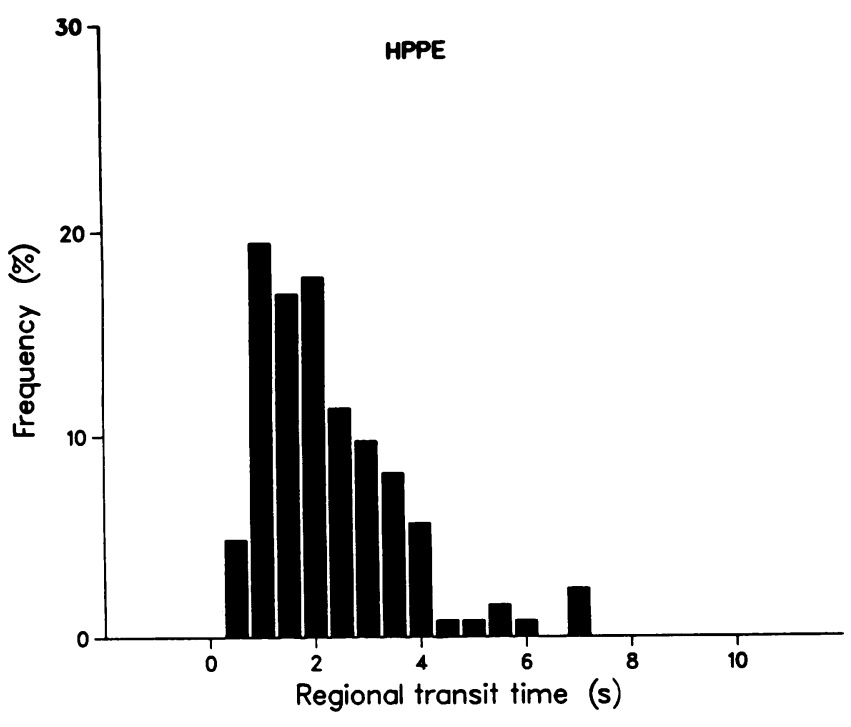

Figure 6. The histogram of regional transit times in the high pressure pulmonary edema group that is not different than the control group (Fig. 4), $P>0.05$.

In summary, the data show that regional blood volume does not increase with increased flow in either oleic acid-induced pulmonary edema or in high pressure pulmonary edema. In OAPE, this could be due to vasoconstriction after vascular injury, local hypoxia, or the fact that edema formation lowers the vascular transmural pressure. In high pressure pulmonary edema, on the other hand, the pulmonary vasculature is already fully expanded by the increased vascular pressure so that there is little further space for increased blood volume with increased flow. The data also show that there is heterogeneity in the regional transit times within the lung in both control and edematous conditions, with the shortest overall regional transit times occurring in oleic acid-induced pulmonary edema.

\section{Acknowledgments}

The authors thank E. M. Baile for her technical assistance and Lee Kowk for her help in preparing the manuscript.

Dr. Tsang is the recipient of the British Columbia Health Care Research Foundation Fellowship. The work was supported by the British Columbia Heart Foundation and the Medical Research Council of Canada (grant MA 4219 to Dr. Montaner).

\section{References}

1. Fishman, A. P., H. W. Fritts, and A. Cournand. 1960. Effects of acute hypoxia and exercise on the pulmonary circulation. Circulation. 22:204-210.
2. Glazier, J. B., J. M. B. Hughes, J. E. Maloney, and J. B. West. 1969. Measurements of capillary dimensions and blood volume in rapidly frozen lungs. J. Appl. Physiol. Respir. Environ. Exercise Physiol. 26:6576.

3. Warrell, D. A., J. W. Evans, R. O. Clark, G. P. Kingaby, and J. B. West. 1972. Pattern of filling in the pulmonary capillary bed. $J$. Appl. Physiol. Respir. Environ. Exercise Physiol. 32:346-356.

4. West, J. B. 1974. Blood flow to the lung and gas exchange. Anaesthesiology. 41:124-138.

5. Hogg, J. C., B. A. Martin, S. Lee, and B. Wiggs. 1984. Regional differences in the time of red blood cell transit through dog lungs. $J$. Appl. Physiol. 59:1266-1271.

6. Ganz, W., R. Donoso, and H. S. Marcus. 1971. A new technique for measurement of cardiac output by thermodilution in man. Am. J. Cardiol. 27:391-396.

7. Schoene, R. B., H. T. Robertson, D. R. Thorning, S. C. Spring meyer, M. P. Hlastala, and I. W. Cheney. 1984. Pathophysiological patterns of resolution from oleic acid injury in the dog. J. Appl. Physiol. 56:472-481.

8. Mcllroy, M. B. 1965. Pulmonary Shunts, Handbook of Physiology, Section III, Vol. 2. W. O. Lenn and H. Rahn, editors. American Physiological Society, Washington, D. C. 65:1519-1524.

9. Muir, A. L., J. C. Hogg, A. Naimark, D. L. Hall, and W. Chernecki. 1975. Effect of alveolar liquid on distribution of blood flow in dog lungs. J. Appl. Physiol. Respir. Environ. Exercise Physiol. 39:885-890.

10. Hollander, M., and D. A. Wolfe. 1973. Non-parametric statistical methods. John Wiley \& Sons, Inc., New York. 115-120.

11. Permutt, S., and R. L. Riley. 1963. Hemodynamics of collapsible vessels with tone: the vascular waterfall. J. Appl. Physiol. 18:924-932.

12. Staub, N. C., H. Nagano, and M. L. Pearce. 1967. Pulmonary edema in dogs, especially the sequence of fluid accumulation in the lungs. J. Appl. Physiol. 22:227-240.

13. Guyton, A. C. 1963. A concept of negative interstitial pressure based on pressures in perforated capsules. Circ. Res. 12:399-414.

14. Guyton, A. C. 1965. Interstitial fluid pressure: II. Pressure-volume curves of interstitial space. Circ. Res. 16:452-460.

15. Bhattacharya, J., M. A. Gropper, and N. C. Staub. 1984. Interstitial fluid pressure gradient measured by micropuncture in excised dog lung. J. Appl. Physiol. Respir. Environ. Exercise Physiol. 56:271-277.

16. Marshall, L., and B. E. Marshall. 1983. Site and sensitivity for stimulation of hypoxic pulmonary vasoconstriction. J. Appl. Physiol. Respir. Environ. Exercise Physiol. 55:711-716.

17. Montaner, J. S. G., J. Tsang, K. G. Evans, J. B. M. Mullen, A. R. Burns, D. C. Walker, B. Wiggs, and J. C. Hogg. 1986. Alveolar epithelial damage. A critical difference between low pressure and high pressure edema. In press.

18. Lynch, J. P., J. G. Mhyre, and D. R. Dantzker. 1979. Influence of cardiac output on the intrapulmonary shunt. J. Appl. Physiol. 46: 315-321.

19. Breen, P. H., P. T. Schumacker, G. Hedenstierna, J. Ali, P. D. Wagner, and L. D. H. Wood. 1982. How does increased cardiac output increase shunt in pulmonary edema? J. Appl. Physiol. Respir. Environ. Exercise Physiol. 53:1273-1280. 